\title{
Reflexões sobre o Movimento de Analise Institucional: subsídios para Educadores ajuizarem sua práxis cotidiana
}

\author{
Reflections on the Institutional Analysis Movement: inputs for educators to judge their daily praxis \\ Reflexiones sobre el Movimiento de Análisis Institucional: aportaciones para que los educadores \\ juzguen su praxis diaria
}

Recebido: 12/10/2021 | Revisado: 19/10/2021 | Aceito: 24/10/2021 | Publicado: 25/10/2021

Márcia Isabel Gentil Diniz
ORCID: https://orcid.org/0000-0003-1980-4597
Universidade Federal Fluminense, Brasil
e-mail:marciagentil@ @uol.com.br
Núcleo de Pesquisas e Extensão em Educação e Saúde Comunitánia/UFF/CNPq, Brasil
Leandro Alcasar Rodrigues
ORCID: https://orcid.org/0000-0003-3523-0570
Secretaria da Educação da Prefeitura Municipal de Jardinópolis, Brasil
Núcleo de Pesquisas e Extensão em Educação e Saúde Comunitária/UFF/CNPq, Brasil
e-mail.leandroalcasar@ yahoo.com.br

\begin{abstract}
Resumo
$\mathrm{O}$ estudo aqui proposto trata-se de uma revisão bibliográfica onde foram consultadas várias literaturas relativas a temática proposta. E em artigos publicados na internet que possibilitaram que o trabalho tomasse forma e se fundamentasse se dispondo a esclarecer profissionais de Educação sobre a referida temática a partir do posicionamento de diversos autores da área, tais como: Baremblitt (1996); Lourau (1996); Ulloa (2012); Bourdieu (1977); Castoriadis (1965) entre outros, considerados estudiosos que buscaram entender e pesquisar de forma mais aprofundada visando o esclarecimento do assunto aqui em questão. Em seguida, através dos estudos aqui desempenhados e das conclusões evidenciadas se pode adquirir subsídios para discussões mais consistentes e aprofundadas sobre tal tema na área educacional.
\end{abstract}

Palavras-chave: Análise institucional; Relações de poder; Educação.

\begin{abstract}
The study proposed here is about a bibliographic review where several literature related to the proposed theme were consulted. And in articles published on the internet that allowed the work to take shape and to be based on, aiming to clarify Education professionals on the aforementioned theme from the position of several authors in the area, such as: Baremblitt (1996); Lourau (1996); Ulloa (2012); Bourdieu (1977); Castoriadis (1965) among others, considered scholars who sought to understand and research in a deeper way in order to clarify the issue at hand. Then, through the studies carried out here and the conclusions evidenced, it is possible to acquire subsidies for more consistent and indepth discussions on this theme in the educational area.
\end{abstract}

Keywords: Institutional analysis; Power relations; Education.

\section{Resumen}

El estudio aquí propuesto es una revisión bibliográfica que consultó varias literaturas relacionadas con el tema propuesto. $\mathrm{Y}$ en artículos publicados en Internet que permitieron que el trabajo tomara forma y se basara en estar dispuesto a aclarar a los profesionales de la educación sobre este tema desde el posicionamiento de varios autores en el área, tales como: Baremblitt (1996); Lourau (1996); Ulloa (2012); Bourdieu (1977); Castoriadis (1965) entre otros, considerados estudiosos que buscaban comprender e investigar en mayor profundidad para aclarar el tema en cuestión. Luego, a través de los estudios realizados aquí y las conclusiones evidenciadas, es posible adquirir subsidios para discusiones más consistentes y profundas sobre este tema en el área educativa.

Palabras clave: Análisis institucional; Relaciones de poder; Educación.

\section{Introdução}

A origem do termo instituição é proveniente do latim, deriva de instituere, que o expressa como: estabelecer, construir, preparar, fundar, regulamentar. Baremblitt 1996 in Mansano (2003; p 156) considera a analise institucional muito 
mais como um movimento institucionalista do que como uma teoria, visto que ela visa "propiciar, apoiar, deflagrar nas comunidades, nos coletivos, nos conjuntos de pessoas, processos de auto-análise e processos de autogestão".

Baremblitt (1996; p 78-79) nos demonstra ainda que:

\begin{abstract}
"Para a Análise Institucional, uma sociedade está ordenada por um conjunto aberto - quer dizer, não totalizável de instituições. Uma instituição é um sistema lógico de definições de uma realidade social e de comportamentos humanos aos quais classifica e divide, atribuindo-lhes valores e decisões, algumas prescritas (indicadas), outras proscritas (proibidas), outras apenas permitidas e algumas, ainda, indiferentes. Essas lógicas podem estar formalizadas em leis, em normas escritas ou discursivamente transmitidas, ou podem ainda operar como costumes, quer dizer, como hábitos não-explicitados. As citadas lógicas se concretizam ou se realizam socialmente em formas materiais ou "corporificadas" que, segundo sua amplitude, podem ser: organizações, estabelecimentos, agentes, usuários e práticas. Cada instituição é universal, ou seja, indispensável para toda e qualquer sociedade, mas para realizar-se em suas formas concretas passa por um momento de particularidade e outro de singularidade única e irrepetível “
\end{abstract}

Nesse sentido, a noção de instituição vai se transformando na medida em que os indivíduos vão se tornando sujeitos da história e da construção social.

Para a Análise Institucional, conforme Lourau (2004a), a implicação instaura uma dimensão de atravessamentos e transformações nas formas subjetivas e objetivas, com a certeza de que "o observador já está implicado no campo de observação, de que sua intervenção modifica o objeto de estudo, transforma-o" (Lourau, 2004b, p. 82).

De acordo com o movimento institucionalista francês, o conceito de instituição é estabelecido por três períodos: i) o momento da universalidade, tendo o teor dos sistemas de normas, os valores que norteiam a socialização, a ideologia, o instituído, enfim; ii) o momento da particularidade, no qual seu conteúdo se resume às determinações materiais e sociais que negam a universalidade, dada no primeiro: é o momento instituinte; iii) o momento da singularidade, de negação da particularidade, em que o conceito de instituição tem por conteúdo as formas organizacionais, jurídicas ou anônimas necessárias para atingir determinado objetivo ou determinada finalidade , é o momento da institucionalização (Lourau, 1996).

\title{
2. Metodologia
}

Quanto ao delineamento metodológico do estudo nos reportamos inicialmente a Ludke e André (1986; p 30) quando afirmam que há formas muito variadas de se registrar informações. Alguns farão apenas anotações escritas (...) os focos de observação nas abordagens qualitativas de pesquisa são determinados basicamente pelos propósitos específicos do estudo, que por sua vez derivam de um quadro teórico geral traçado pelo pesquisador de acordo com Ludke e André (1986; p30).

Em pesquisas bibliográficas costuma-se consultar várias literaturas relativas ao assunto em estudo, que possibilitam que o estudo proposto seja fundamentado. Para Fonseca (2002, p. 32) a pesquisa bibliográfica é feita a partir do levantamento de referências teóricas já analisadas, e publicadas por meios escritos e eletrônicos". A sua finalidade é fazer com que o pesquisador entre em contato direto com todo o material escrito sobre um determinado assunto, auxiliando o cientista na análise de suas pesquisas ou na manipulação de suas informações. Ela pode ser considerada como o primeiro passo de toda a pesquisa científica.

Cabe salientar que a natureza do estudo elaborada se trata de uma revisão narrativa de caráter descritivo e, portanto, sua natureza está voltada para temática analise institucional na educação seguindo alguns passos metodológicos para sua consecução. Foram definidos como critérios de elegibilidade para inclusão dos artigos: artigos nos idiomas português e espanhol; relatos de artigos sobre temáticas de analise institucional e analise institucional em educação e em escolas. As referências dos artigos selecionados foram cuidadosamente examinadas com intento de se localizar outros artigos importantes 
que atendessem aos critérios anteriormente descritos. Após a seleção dos artigos conforme os critérios de elegibilidade previamente definidos, foram seguidos os seguintes passos: leitura exploratória, leitura seletiva e escolha do material que melhor conferisse com o foco de análise buscado nos textos e, ao final dessas etapas se elaborou então a redação final do artigo.

\section{Desenvolvimento}

$\mathrm{Na}$ revisão da literatura, (...) sentiu-se a necessidade de contato direto com um local que realiza intervenções neste sentido (...), pôde-se perceber as diversas dificuldades que circulam no enfrentamento do problema. "Sentir" essa vivência nos sensibilizou ainda mais e, sobretudo, mobilizou mais reflexões, as quais enriqueceram os conhecimentos. PASINI (2020;n/p )

Contudo, para o aprofundamento desse assunto se faz necessário inicialmente a compreensão sobre o Movimento Institucionalista ou Instituinte. O Movimento Institucionalista é um conjunto heterogêneo, etimológico e polimorfo de orientações, entre as quais é possível se encontrar pelo menos uma particularidade que se configura em sua aspiração que é deflagrar, sustentar e apurar os processos dos coletivos sociais.

No entanto, devido ao seu caráter por si mesmo libertário e com um modo epistemológico singular, explicá-lo é uma tarefa árdua, pois os processos de interação humana e de funcionamento da sociedade já são intrinsecamente complexos para que se possa descrevê-los de modo unidimensional e superficial.

Quando se trata de referir à complexidade da sociedade basta que se estabeleça uma comparação entre a vida social em sociedades primitivas com outras consideradas modernas e isso não é uma tarefa nada simples, acrescido a isso podemos também refletir sobre o saber que foi rapidamente acumulado nos últimos tempos de forma rápida e intensa, levando a discrepâncias desproporcionais ao compará-las.

Tal ocorrência leva uma produção de conhecimento através de seu próprio saber fazendo com que os detentores desses conhecimentos os coloquem a serviço do próprio, gerando assim poder através da hegemonia imposta pelos mesmos e configurando forças dominantes em nossa sociedade.

Assim sendo, a sociedade civil tem sentido uma verdadeira "desapropriação" de um saber que lhes é próprio e acumulado sobre a sua própria vida, como se este conhecimento fosse incerto, carente e tão precário que a partir do conhecimento tecnológico foi se relegando e subordinando o saber coletivo aos saberes dos experts que os tornam incapazes de gerenciar sua própria existência. Diante dessa situação, as comunidades já não sabem do que realmente necessitam e anseiam, pois passam a inculcar que suas necessidades são as ditadas pelos experts.

Com isso, os coletivos têm alienado o saber sobre sua própria existência e condições de vida ficando reféns e limitados e não sabem mais o que de fato são suas autênticas necessidades, pois se perderam perante o processo necessário de organização social que os fortalece para resolverem o que querem e o porquê querem.

O processo de análise ainda que de forma superficial passa agora a fazer todo sentido quando se pensa em conjecturas para que as comunidades, como protagonistas de suas dificuldades, interesses, e demandas, possam emitir, abarcar, ou recuperar um pensamento e uma linguagem própria que lhes admita saber acerca de sua própria vida.

Este método de análise das comunidades é simultâneo ao processo de auto-organização, em que ela se pronuncia, e se aparelha para estabelecer os dispositivos indispensáveis para determinar, ela mesma, ou para obter os recursos de que necessita para o custeio e a benfeitoria de sua vida.

Na medida em que essa organização é resultado e, ao mesmo tempo, um movimento análogo com a apreensão dada pela análise, ela também não é uma façanha projetada de cima para baixo, nem de fora, mas ordenada pela diversidade do 
coletivo. Essa auto-análise e essa autogestão não exprimem que os coletivos devam prescindir por completo dos experts porque, sem dúvida, com sua disciplina e seus instrumentos, eles têm acumulado uma quantidade de conhecimento importante e não inteiramente alienado, não necessariamente induzido, ou seja, pode ser produtivo de acordo com a intencionalidade e instituindo-se uma relação de horizontalidade, somente assim os experts terão um lugar dentro das comunidades com seus saberes plenamente integrados.

Souza $(2020 ; n / p)$ refere ainda do importante papel do gestor nas Instituições:

“O papel do gestor é fundamental dentro da instituição, e este não deve ser visto como um profissional que dá ordens, e sim aquele que desenvolve seu trabalho em prol de atender, as questões burocráticas, pedagógicas e também da comunidade em que ele está inserido. Pois ele é responsável por promover a boa relação entre a comunidade escolar. Ao analisar a narrativa do gestor foi possível perceber que o mesmo não só se destina a atender somente as questões burocráticas, mas também pedagógicas e do cotidiano escolar.” (Souza, 2020, p.6)

Percebe-se então que autogestão e auto-análise devem permanecer constantemente articuladas apesar de serem dois atos diferenciados para que sua execução dentro das comunidades seja factível de ser implementadas necessitam estar coarticuladas.

No Brasil, existe um obstáculo para essa articulação, pois o saber acadêmico costuma desqualificar o coletivo funcionando a serviço dos interesses maiores. Sendo assim, as diferentes realidades sociais são criadas por sujeitos, e estes sabem muito bem falar por si, mesmo que para isso tenham que superar algumas barreiras hierárquicas construídas no decorrer da história e que, de certa maneira, contribuíam para desqualificar esta fala. Sobre isso Foucault (1979) observa:

"Ora, o que os intelectuais descobriram recentemente é que as massas não necessitam deles para saber; elas sabem perfeitamente, claramente, muito melhor do que eles; e elas o dizem muito bem. Mas existe um sistema de poder que barra, pró́be, invalida esse discurso e esse saber. Poder que não se encontra somente nas instâncias superiores da censura, mas que penetra muito profundamente, muito sutilmente em toda a trama da sociedade. Os próprios intelectuais fazem parte desse sistema de poder, a "idéia" de que eles são agentes da "consciência" e do discurso também faz parte desse sistema. O papel do intelectual não é mais o de se colocar "um pouco na frente ou um pouco de lado" para dizer a muda verdade de todos; é antes o de lutar contra as formas de poder exatamente onde ele é, ao mesmo tempo, o objeto e o instrumento; na ordem do saber, da "verdade", da "consciência", do discurso". (Foucault, 1979, p.71).

De acordo com Foucault, a existência de um sistema de poder próprio ao exercício intelectual subordina a "fala das massas", inferiorizando-as frente ao discurso científico e acadêmico. Nesta percepção, pouco importa se o intelectual "se coloca um pouco na frente ou um pouco ao lado" das massas, pois, autônomo da posição assumida, seja negando ou não o papel de porta-voz dos anseios dos grupos socialmente marginalizados, o discurso intelectual se esboça como detentor de um poder de verdade dotado de uma aura. (Patrocínio; 2010, n/p)

A auto-análise ressalta que as comunidades, como protagonistas de seus problemas, necessidades, interesses, desejos e demandas, possam enunciar e compreender, adquirir ou readquirir um pensamento e um vocabulário próprio que lhes permita saber acerca de sua vida, ou seja: não se trata de que alguma pessoa venha de fora ou de cima para dizer-lhes quem são, o que podem, o que sabem, o que devem pedir e o que podem ou não conseguir.

Este processo de auto-análise das comunidades é simultâneo ao processo de auto-organização, em que ela se articula, se institucionaliza, e se organiza para construir os dispositivos necessários para produzir, ou para conseguir os recursos de que precisa para a manutenção e o melhoramento de sua vida.

Na medida em que essa organização é conseqüência e, ao mesmo tempo, um movimento paralelo com a compreensão dada pela auto-análise, ela também não é feita em qualquer direção, mas elaborada no próprio seio heterogêneo do coletivo 
interessado. A auto-análise e a autogestão não significam necessariamente que os coletivos devam prescindir por completo dos experts porque, sem dúvida, com sua disciplina e seus instrumentos, eles têm acumulado conhecimento e esse não é necessariamente distorcido.

O que se evidencia nessa situação é que esses conhecedores muitas vezes mais interessados em se colocarem a emprego das entidades e forças influentes da sociedade acabam por gerar complexidades na organização social por si mesma.

O Institucionalismo é a demonstração extrema, de inquietações com relação a hegemonia do pensamento científico e de suas distintas particularidades, amparando a produção de todos os saberes, abrangidos, os que permanecem em "estado prático" nas práticas laicas, místicas e etc.

Nesse sentido, se pode aquilatar a dificuldade para quem se interessa por este estudo, os problemas em acolher e apreender a polissemia que adquirem diversos campos semânticos provenientes de distintas escolas.

Evidencia-se então toda essa complexidade quando se está diante de um composto de todos os saberes de uma época, com a inclusão também dos saberes não-científicos. Sendo assim, a gênese de um institucionalista é interminável.

Independentemente da técnica utilizada para a abordagem institucional, o autor Escolar (2010) argumenta que: "a análise institucional define a instituição como qualquer lugar de produção e reprodução das relações sociais da produção. É para dizer que, por um lado, se opõe à interpretação Durkheim da instituição como uma "coisa" e, por outro, para o marxismo reducionista" (Escolar, 2010, p. 239)

Cabe descrever no desenvolvimento do artigo, que é importante no aprofundamento das questões aqui desenvolvidas citar que existe toda a problemática do capital que faz a dissensão entre educação produtiva e a não produtiva enquanto modo de produção do conhecimento como demonstra Pereira et al., 2019.

"Sob este modo de produção, o conhecimento para a produção torna-se também propriedade da classe dominante. A
própria universalização do ensino, uma bandeira da burguesa nascente, apresentava como objetivo inicial possibilitar
ao trabalhador o domínio do código escrito. Com o aumento da incorporação da ciência no processo produtivo os
saberes necessários ao desempenho das atividades produtivas se complexifica e a educação destinada aos
trabalhadores torna-se mais abrangente. Todavia, ao trabalhador continua sendo dado um saber parcelado e
descontextualizado, que lhe serve apenas para a realização de tarefas necessárias ao capital". (Pereira et al., 2019. p.5.)

Faz-se necessário aqui abordar individualmente dentro do enfoque da análise institucional ortodoxa, os autores vinculados a Sociedade Francesa de Análise Institucional. Ao se abarcar institucionalmente a dinâmica de uma organização é imperativo compreender, e, especificar a solicitação que esta organização faz de uma análise e de uma intervenção.

Tendo se como meta se refletir ainda que provisoriamente quais sejam as feições conscientes, e claras deste apelo, e qual é o seu aspecto inconsciente e/ou não-dito. Assim se denomina tal proposição de análise de demanda, que é um dos primitivos caminhos para perceber em que consiste a situação conflitiva desta organização solicitante.

No que dizem respeito à Instituição, as perspectivas de definição e análise são diversas, por isso é necessário especificar o que entendemos conceitualmente, ou seja, o que vamos conceber como uma instituição vai nos permitir saber de onde falaremos. De um ponto de vista amplo e geral, se interpreta " instituições como formações sociais, culturais, psíquicas" (Garay, 1997, p. 2).

Contudo, para fazê-lo, o Institucionalismo ressalta a obrigação de se ter presente a idéia de que a demanda não é instintiva, a demanda não é o primeiro passo de um processo: ela é determinada, de tal modo que existe um passo anterior à demanda que é a oferta. A demanda não existe por si. Quando alguns psicanalistas falam hoje em análise da demanda como a expressão do desejo, eles não têm aparelho teórico para pensar que o processo não começa aí, que essa demanda de análise foi produzida pela oferta prévia de análise, e está marcada, modulada, determinada, desde o princípio, por esta oferta. De modo 
que para abranger a demanda de análise institucional de uma organização é mandatório, antes, incluir a auto-análise e a captação de como a organização analítica originou a questão.

O movimento institucionalista francês, propõe uma análise da sociedade e das instituições, partindo de sua crítica à noção de instituição até então discutida pelos movimentos antecedentes.

Afirma a instituição como sendo a forma assumida pela produção e reprodução de relações sociais em um dado modo de produção, como um reflexo da organização das relações de produção nessa sociedade. Nesse sentido, se sobrepõe aos marxistas, criticando-os, porém, por autonomizarem o momento da particularidade ao subestimar a ação recíproca entre superestrutura e infra-estrutura (Barbier, 1985; Lourau, 1996).

O movimento institucionalista nega a oposição entre o particular e o geral que suprime o terceiro período do conceito de instituição - o momento da singularidade e, sobretudo a ação recíproca dos três momentos. Segundo seus autores, com essa oposição se causam antinomias que só poderiam ser decididas pelo predomínio dado à estrutura (ou às normas, ao instituído), ou à ação (ao indivíduo, ao instituinte).

As noções de instituído e instituinte foram introduzidas ao conceito de instituição por Castoriadis em 1965. E é por influência deste que Lapassade (1977) mostra a instituição como a organização das relações sociais entre os indivíduos; o conjunto de normas instituídas que regem a organização, apontando a existência do instituinte como um campo de luta e de conflitos dentro da instituição.

De acordo com (Middaugh 1990) se pode referir Análise Institucional como: "A soma de todas as atividades que visam descrever empiricamente todo o espectro de funções educacional, investigação, administrativo e apoio". Nesse sentido, a análise institucional tem de ter uma visão estruturada da atividade organizacional, bem como ter um processo e procedimentos para analisar que olhe tem integridade em si mesmo. Para alcançar este olhar estruturado, um enquadramento conceptual para pensar sobre o que são as organizações e como funcionam. (Herrera,2017, p2)

Há que se ressaltar também a contribuição ofertada pelos estudos de Ulloa (2012) analisando a dinâmica institucional. Tal autor é conhecido pela obra Novela clínica psicanalítica: história de uma prática e destaca a parte principal do seu trabalho: as chamadas articulações institucionais. As próprias articulações começam a ser úteis para o trabalho clínico institucional quando são patológicas. Uma articulação patológica constitui uma fração, isto é, uma fratura institucional.

Todas as articulações estão intimamente relacionadas com as normas institucionais quando propõe, por exemplo, a análise instituições diversas incluindo-se à Escola, na visão de Ulloa em seu trabalho Psicologia das Instituições (2012).

O mesmo autor define as instituições como algo ambíguo, uma vez que pode designar simultaneamente uma regularidade de conduta e um sistema de regras, costumes e tradições. Pode também ser definida como uma organização social, com o âmbito que este termo normalmente tem, ou seja, instituições como o conceito que conhecemos: uma geografia de organização comum e uma gestão de tempo e responsabilidades, com objetivos a atingir e meios adequados para o efeito, todos regulados por um código e por regras explícitas. A designação mais adequada parece, então, ser a das organizações institucionais.

Bourdieu (1977) em seus estudos menciona a relação institucional com a prática educacional quando refere que:

"Um instrumento fundamental de continuidade histórica, a educação, considerado como um processo através do qual a reprodução da arbitrariedade cultural é realizada ao longo do tempo através da produção de hábitos, que produz práticas de acordo com a arbitrariedade cultural (isto é, transmitir a formação como informação capaz de "informar" duradouramente os destinatários), é o equivalente, no domínio da cultura, à transmissão do capital genético no domínio da biologia: sendo o habitus análogo ao capital genético, a inculcação que define a realização da Ação Pedagógica é análoga à geração na medida em que transmite uma informação que gera informação análoga" 
Prossegue referindo que fato de as relações de força estar na sua origem, não só da ação pedagógica, mas também da ignorância da verdade objetiva da ação pedagógica. Ignorância que determina o reconhecimento da legitimidade da ação pedagógica e que, como tal, constitui a sua condição de exercício.

Corroborando com as idéias de Bourdieu em 1977 o autor Saviani (1983, p. 35-36) alerta que, sendo a escola um instrumento de reprodução das relações na sociedade capitalista, necessariamente reproduz a dominação e a exploração, porém, é preciso superar essa função colocando nas mãos dos educadores uma arma de luta capaz de permitir-lhes o exercício de um poder real, ainda que limitado.

Nesse caso, cabe aos cursos de formação garantir aos educadores sólida fundamentação teórica e ampla reflexão filosófica; aos professores, cabe munir-se de aprofundados conhecimentos que lhes permitam tomar a educação como fundamento e compreender a realidade humana. É preciso, também, garantir um ensino da melhor qualidade possível nas condições históricas atuais. Trata-se de promover o homem, ou seja, de dar à classe trabalhadora as condições necessárias ao entendimento da sociedade. Tem que haver, então, um empenho para que a escola funcione bem, para que haja métodos de ensino eficazes. Nesse sentido, Saviani (1983, p.72-73) elabora o Método da Prática Social que estimulará [...] a atividade e a iniciativa dos alunos sem abrir mão, porém, da iniciativa do professor; favorecerá o diálogo dos alunos entre si e com o professor, mas sem deixar de valorizar o diálogo com a cultura acumulada historicamente; levarão em conta os interesses dos alunos, os ritmos de aprendizagem e o desenvolvimento psicológico, mas sem perder de vista a sistematização lógica dos conhecimentos, sua ordenação e gradação para efeitos do processo de transmissão-assimilação dos conteúdos cognitivos.

Gramsci denuncia ainda a crise da escola tradicional devido à industrialização que trouxe "sua própria escola interessada, profissionalizante, técnica e ideologicamente imediatista" (Nosella, 2004, p. 166).

Tal autor Nosella (2004, p. 170) prossegue asseverando que a escola unitária, proposta por Gramsci, fundiria a característica formativo-humanista com a sua dimensão prático-produtiva.

Vale ressaltar que uma sociedade ideal seria composta da inteira distribuição equitativa de todos os recursos, sejam eles naturais ou sociais, implantando um sistema social com indivíduos usufruindo de renda, saúde e educação, em um cenário justo, assim desejado. Chaves e Almeida (2020;n/p)

\footnotetext{
“A tarefa de analisar a instituição desde esse duplo jogo de "ator e analisador", (...) remete para os afetos tais como o amor, ódio, inveja, alegria, sofrimento, prazer. Quem pode afirmar a presença de uma identidade entre as experiências daqueles que afirmam ser dominados por tais afetos? Ninguém, exceto uma lei, pré-existente ao conjunto de sujeitos que liga estes significadores a um significado que supostamente designa esse afeto. Isto distingue um setor linguístico em que o mesmo sinal se refere aos referenciais, cuja equivalência não garante nada, o que redobre a violência que "ter de falar" impõe à "psique". A transformação do afeto em sentimento é o resultado deste ato de linguagem que impõe um corte radical entre o registo pictográfico e o registo do cenário no sentido: esse corte é por si só, independente da voz e das vozes a que o sujeito deve a contribuição linguística". (Piera Castoriadis - Aulagnier 1975).
}

\section{Considerações Finais}

Com essa revisão, se pode entender que o alvo de uma intervenção em análise institucional consiste em suscitar o aparecimento dos conflitos e contradições existentes no interior das instituições e dos grupos sociais, o que acontece mediante o questionamento das relações de poder e da consulta permanente sobre os caminhos que o grupo deseja trilhar.

Quando se lança um olhar diferenciado com os conhecimentos aqui apresentados sobre análise institucional é importante se ter sempre claro que, como processo histórico de construção social, a instituição educação é revelada no seu modo de produção e na prática concreta dos profissionais que atuam em suas organizações ou estabelecimentos. 
Deste modo, a institucionalização em educação deve se propor a estabelecer um exercício, a entusiasmar uma transformação na prática da destreza educacional praticada atualmente e não exclusivamente no processo de avaliar ou não avaliar quem são os educandos "mais ou menos inteligentes" por métodos que por si somente já se consagraram como ultrapassados.

A escola precisa se abrir para o acolhimento a todos sem distinções valorizando o saber popular dos que se encontram a margem do processo educativo, retirando das práxis educativas somente as suais estratégias que estão contidas na literatura e que não saem dela para o cotidiano das salas de aula e desse contexto para a vida.

O conhecimento e a ousadia do docente precisam ser colocados a prova, incitados. Tal iniciativa pode colaborar para o movimento contínuo de transformação das práticas educacionais tão necessárias na atualidade.

Este estudo permitiu-nos ter uma visão mais contemporânea sobre como através do estabelecimento de uma comunicação efetivamente dinâmica, se obtém a capacidade de se instituir um ambiente favorável e real que terá um impacto positivo na eficiência do trabalho educativo com as todos os segmentos populacionais em situações de crise social, especialmente no que concerne a Educação. Através da investigação realizada mesmo com escassa literatura sobre a temática no espaço educacional, tal texto nos permitiu reafirmar e sugerir a geração de uma agenda mais aprofundada de investigações sobre tal temática relacionado-a ao ensino no Brasil, como acontece noutros países do mundo

\section{Referências}

Baremblitt, G. (1996). Compêndio de análise institucional e outras correntes. Rosa dos Tempos.

Bourdieu, P. (1997). La reproducción. Elementos para una teoría del sistema de enseñanza. Laia Barcelona.

Castoriadis, C. (1965). A instituição imaginária da sociedade. Paz e Terra: 418. Tradução de L'Institution imaginaire de la societé por Guy Reynaud.

Castoriadis, P., \& Aulagnier, P (1975). "La violencia de la interpretación" Amorrortu In: Kremer, A. Análisis institucional, un olvido para recordar y comprender://www.acheronta.org/acheronta19/kremer.htm.

Chaves, A. B. P., \&Almeida, L. J. S. de. (2020). A Política do Retrocesso: educação e desigualdade no Brasil. Research, Society and Development, 9(8), e548985957, 2020. 10.33448/rsd-v9i8.5957.

Escolar, C. (2010). Institución, implicación, intervención. Revisando y revisitando las categorías del Análisis Institucional. Acciones e investigaciones Sociales, 28, 235-250

Fonseca, J. J. S. (2002). Metodologia da pesquisa científica. UEC.

Foucault, M. (1979). Microfísica do poder. Edições Graal.

Garay, L. (1997). Conocer las instituciones. Algunas ideas para el diagnóstico. Ferreyra

Herrera, R. (2017). Apuntes Sobre Análisis Institucional Indicadores, Funciones, Visión Y Modelos. Dirección De Análisis Y Desarrollo Institucional. Universidad de La Frontera.

Lapassade, G. E. (1977). Encuentro Institucional. Em Lourau, R. et alli: Análisis Institucional y Socioanálisis, Nueva Imagem.

Lourau, R (1996). A análise institucional. Vozes, 1996.

Lourau, R. (2004a). Implicação-Transdução. In S. Altoé (Org.), René Lourau: analista institucional em tempo integral (pp. 212-223). Hucitec.

Lourau, R.(2004b). Objeto e método da Análise Institucional. In S. Altoé (Org.), René Lourau: analista institucional em tempo integral (pp. 66-86). Hucitec.

Lüdke, Menga. (1986). L975p Pesquisa em educação: abordagens qualitativas I Menga Lüdke, Marli E. D. A. André. EPU. https://edisciplinas.usp.br/plugi nfile.php/4 091392/mod_resource/content/1/Lud_And_cap3.pdf.

Mansano, S. R. V. (2003). Análise institucional: relato de uma experiência com jovens. Psicologia em Revista, 10(14), 155-160.

Middaugh, M (1990). The Nature and Scope of Institutional Research. En New Directions for Institutional Research. $\mathrm{N}^{\circ} 66$. http://analisis.ufro.cl/images/planD/3/Apuntes-sobre-Analisis-Institucional.pdf.

Nosella, P (2004). A Escola de Gramsci. (3a ed.), Cortez. 
Research, Society and Development, v. 10, n. 14, e83101421696, 2021

(CC BY 4.0) | ISSN 2525-3409 | DOI: http://dx.doi.org/10.33448/rsd-v10i14.21696

PasinI, A. L. \& Weiler et al. (2020) Suicídio e depressão na adolescência: fatores de risco e estratégias de prevenção. Research, Society and Development, 9(4), e36942767. http://dx.doi.org/10.33448/rsd-v9i4.2767.

Patrocínio, P. R. T. (2020). A voz da periferia e a função do intelectual. https://www.ufjf.br/darandina/files/2010/12/A-voz-da-periferia-e-afun\% $3 \% \mathrm{~A} 7 \% \mathrm{C} 3 \% \mathrm{~A} 30-$ do-intelectual.pdf.

Pereira, M. E. K. dos S et al. (2019). Trabalho como princípio educativo e a superação da dualidade educacional brasileira. Research, Society and Development, 8(12), e098121486, 10.33448/rsd-v8i12.1486.

Saviani, D. (1983). Escola e Democracia. Cortez Autores Associados.

Souza, M. I. M. de. (2020) O fazer do gestor escolar: desafios e possibilidades de sua atuação profissional, enquanto facilitador do processo de ensino-aprendizagem. Research, Society and Development, 9(7), e335973900, 2020. 10.33448/rsd-v9i7.3900.

Ulloa, F. (2021) O - Ps. De Las Instituciones. BuenasTareas.com. https://www.buenastareas.com/ensayos/Ulloa-Ps-De-Las-Instituciones/5241615.

Ulloa, F. (2012). o. novela clínica psicoanalítica: Historial de una prática. Libros del Zorzal. 